\title{
Retraction Note: Characteristics of mountain climate change and optimization of agricultural tourism management based on satellite Internet of Things
}

\author{
Xia Zhang ${ }^{1}$
}

Published online: 29 November 2021

(c) Saudi Society for Geosciences 2021

Retraction Note: Arabian Journal of Geosciences (2021) 14: 1625

https://doi.org/10.1007/s12517-021-07708-w

The Editor-in-Chief and the Publisher have retracted this article because the content of this article is nonsensical. The peer review process was not carried out in accordance with the Publisher's peer review policy. The author has not responded to correspondence regarding this retraction.

The original article can be found online at https://doi.org/10.1007/ s12517-021-07708-w.

Xia Zhang

ylgltm@126.com

1 School Of Management, Yulin University, Yulin 719000,

Shaanxi, China 